was still apparent 72 hours after treatment, even in the absence of FDCs (Fig. 1a), perhaps indicating accumulation of $\mathrm{PrP}^{\mathrm{Sc}}$ in extracellular sites or in macrophages ${ }^{3}$.

A single intraperitoneal treatment of mice with LT $\beta R$-Ig 3 days before or 14 days after intraperitoneal challenge with scrapie ('-3 dpi' or ' +14 dpi', respectively) significantly extended incubation periods by $29 \%$ and $23 \%$, respectively, compared with that of control mice treated with human immunoglobulin (hu-Ig) (Fig. 1c). Unexpectedly, treatment as late as 42 days after challenge also significantly extended the incubation period, by $12 \%$ (Fig. 1C). After intracerebral scrapie challenge, treatment with LT $\beta R$-Ig had no significant effect on disease development (Fig. 1b), confirming that blockade of the LT $\beta R$ pathway has no effect on scrapie pathogenesis in the brain.

At 70 days after intraperitoneal scrapie challenge, we collected two spleens from each treatment or control group (Fig. 1C). All spleens from control mice contained high levels of infectivity (4.9-5.7 log intracerebral 50\% infectious dose (ID50/g, as estimated from incubation period in groups of 12 intracerebrally injected assay mice). Treatment of mice with LT $\beta R$-Ig 3 days before scrapie challenge temporarily blocked replication in the spleen, as infectivity was undetectable $(<2.0 \mathrm{log}$ intracerebral $I D_{50} / g$ ) in the two spleens collected 70 days after challenge, about 40 days after the expected reappearance of mature FDCs. However, spleens from the groups treated at 14 and 42 days contained high levels of infectivity (4.9-5.7 log intracerebral $\left(I_{50}\right) / g$, even though the incubation period was extended in each case.

Multiple weekly doses of LT $\beta R$-Ig have recently been reported to interfere with pathogenesis in the spleen in another mouse scrapie model ${ }^{8}$, but the interpretation of this study may be complicated by long-term antibody responses to the reagent. Here we have shown that a single treatment with LT $\beta$ R-Ig before or shortly after peripheral scrapie challenge was sufficient to substantially slow the disease. This is most likely to be due to a loss of mature FDCs, although effects on expression of $\mathrm{PrP}^{c}$ directly or on other cell types in the spleen cannot be entirely excluded. These observations indicate that strategies that temporarily inactivate FDCs, such as blockade of the LT $\beta$ R pathway ${ }^{7}$, may present an opportunity for early intervention in peripherally transmitted TSE diseases, for example variant Creutzfel dt-Jakob disease.

\section{Neil A. MABBotT ${ }^{1 *}$, FABienne}

MACKAY ${ }^{2}$, FIONA MINNS ${ }^{1} \&$

MOIRA E. BRUCE ${ }^{1}$

${ }^{1}$ Institute for Animal Health

N europathogenesis Unit

Ogston Building

West M ains Road

Edinburgh EH9 3JF, Scotland, UK

Email: neil.mabbott@bbsrc.ac.uk

${ }^{2}$ Boigen Inc.

14 Cambridge Center

Cambridge, Massachusetts 02142, USA

F.B. Present address: Garvan Institute of

M edical Research

Darlinghurst, NSW Australia

1. Brown, K.L. et al. Scrapie replication in lymphoid tissues depends on PrP-expressing follicular den- dritic cells. Nature Med. 5, 1308-1312 (1999).

2. Mabbott, N.A. et al. Tumor necrosis factor-alphadeficient, but not interleukin-6-deficient, mice resist peripheral infection with scrapie. J. Virol. 74, 3338-3344 (2000).

3. Jeffrey, M., MCGovern, G., Goodsir, C.M., Brown, K.L. \& Bruce, M.E. Sites of prion protein accumulation in scrapie-infected mouse spleen revealed by immuno-electron microscopy. J. Pathol. (in the press).

4. Hill, A.F. et al. Investigation of variant Creutzfeldt-Jakob disease and other prion diseases with tonsil biopsy samples. Lancet 353 183-189 (1999)

5. Endres, R. et al. Mature follicular dendritic cell networks depend on expression of lymphotoxin $\beta$ receptor by radioresistant stromal cells and of lymphotoxin $\beta$ and tumour necrosis factor by $B$ cells. J. Exp. Med. 189, 159-168 (1999).

6. Force, W.R. et al. Mouse lymphotoxin-beta receptor. J. Immunol. 155, 5280-5288 (1995)

7. Mackay, F. \& Browning, J.L. Turning off follicular dendritic cells. Nature 395, 26-27 (1998).

8. Montrasio, F. et al. Impaired prion replication in spleens of mice lacking functional follicular dendritic cells. Science 288, 1257-1259 (2000).

9. Kosco-Vilbois, M.H., Zentgraf, H., Gerdes, J. \& Bonnefoy, J.-Y. To "B" or not to "B" a germinal center? Immunol. Today 18, 225-230 (1997).

10. Farquhar, C.F., Somerville, R.A. \& Ritchie, L.A. Post-mortem immunodiagnosis of scrapie and bovine spongiform encephalopathy. J. Virol. M eth. 24, 215-222 (1989)

\title{
Special Focus on malaria
}

Malaria, an age-old, potentially fatal disease transmitted by mosquitoes that kills an estimated 2.6 million people annually, is now high on the agenda of the biomedical community.

The US Congress is backing development of perhaps the only medicine with a real chance of thwarting

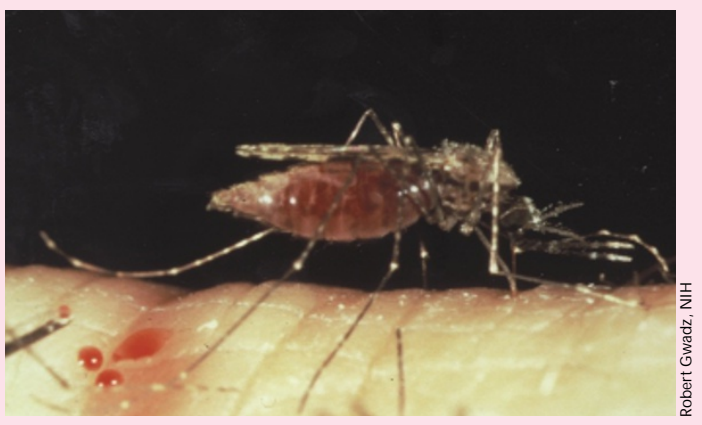
this infectious disease, a vaccine, now that it recognizes the disease as a threat to domestic health because of its global proportions (page 723). And hundreds of the world's senior scientists have appealed to the United Nations Environment Programme to re-think its pro-posed ban on the use of DDT in tropical countries, as outlined in a controversial Commentary in this issue (page 729).

To mark the importance of malaria and to summarize the current research activity aimed at understanding and eventually tackling the disease, $\mathrm{N}$ ature Medicine has published a Special Focus on malaria.

\section{Go to www.medicine.nature.com}

Visitors to the website have free access to the material presented there. This includes the DDT Commentary by Amir Attaran and colleagues, a special web-only status report on malaria vaccine development by Stephanie James and Louis Miller at the National Institutes of Health, plus a selection of the most important manuscripts, News \& Views articles, News stories and Commentary pieces on malaria research published in the Nature group of journals. The site also contains summaries of some of the best research articles published in other, non-Nature group journals.

In addition to reading the malaria Special Focus, visitors to the website can read weekly news updates on general subjects of interest to the biomedical community on the Nature M edicine homepage, accessed by the Biomedical News button. 